Check for updates

Cite this: RSC Adv., 2018, 8, 24627

\title{
Polymorphism, phase transformation and energetic properties of 3-nitro-1,2,4-triazole $\uparrow$
}

\author{
Pengcheng Zhang, (D) ${ }^{a}$ Xiuxiu Zhao, ${ }^{a}$ Yao Du, (D) a Michael Gozin, (D) ${ }^{\text {b }}$ Shenghua Li*a \\ and Siping Pang (D) *a
}

We report the preparation, analysis, and phase transformation behavior of polymorphs of 3-nitro-1,2,4triazole. The compound crystallizes in two different polymorphic forms, Form I (tetragonal, $P 4_{1} 2{ }_{1} 2$ ) and Form II (monoclinic, $P 2_{1} / c$ ). Analysis of the polymorphs has been investigated using microscopy, differential scanning calorimetry, in situ variable-temperature powder X-ray diffraction, and single-crystal X-ray diffraction. On heating, Form II converts into Form I irreversibly, and on further heating, decomposition is observed. In situ powder X-ray diffraction studies revealed that Form II transforms to Form I above $98^{\circ} \mathrm{C}$, indicating that Form I is more stable than Form II at high temperature. Form II of 3nitro-1,2,4-triazole has good detonation properties $\left(V_{\text {det }}=8213 \mathrm{~m} \mathrm{~s}^{-1}, P_{\mathrm{C}-\mathrm{J}}=27.45 \mathrm{GPa}\right)$, and low sensitivity (IS $>40 \mathrm{~J}, \mathrm{FS}=360 \mathrm{~N}, \mathrm{ESD}=29 \mathrm{~J}$ ), which make it a competitive candidate for use as a new insensitive explosive.

Received 14th May 2018

Accepted 25th June 2018

DOI: $10.1039 / \mathrm{c} 8 \mathrm{ra04116d}$

rsc.li/rsc-advances

(detonation velocity is 7541) are two well-known insensitive explosives; however, both of them have relatively low energy content.

Hence new insensitive compounds with high-energy-density Crystal polymorphism, the ability of a compound to exist in different crystalline forms that have different arrangements and/ or conformations of molecules in the solid state, is a widespread phenomenon that has gained much interest in both academic and industrial research. ${ }^{1}$ In particular, the polymorphs of energetic materials have an important influence on energetic properties (insensitivity, higher density, higher energy).

Energetic materials (explosives and propellants) are used extensively for both civilian and military applications. Some major considerations for successful weaponization of energetic materials include performance (e.g. energy density, rate of energy release), long term storage stability, and insensitivity to unwanted initiation. Therefore, a compromise or a balance of the energy-safety contradiction appears generally in practical applications. ${ }^{2}$ The term "Insensitive Munition (IM)" is used to describe munitions, which are safe to handle and difficult to initiate accidentally, but still have the power to fulfil the mission requirements to complete the mission. ${ }^{3}$ Selection of explosives that have inherently lower sensitivity to shock and/or thermal decomposition will reduce the vulnerability of the resulting formulation. TNT (2,4,6-trinitrotoluene, detonation velocity is 7363) and TATB (1,3,5-triamino-2,4,6-trinitrobenzen)

${ }^{a}$ School of Materials Science \& Engineering, Beijing Institute of Technology, Beijing 100081, China.E-mail: pangsp@bit.edu.cn; lishenghua@bit.edu.cn

${ }^{b}$ School of Chemistry, Faculty of Exact Science, Tel Aviv University, Tel Aviv, 69978, Israel

$\dagger$ Electronic supplementary information (ESI) available: For ESI and crystallographic data in CIF. CCDC 1848407 and 1848408. See DOI: 10.1039/c8ra04116d energetic nitrogen heterocyclic group, 1,2,4-triazole features high heats of formation, good thermal stabilities, big densities, which make it a highly efficient structural unit in the development of high-energy-density materials and many energetic triazole based derivatives have been synthesized. ${ }^{4}$ However, the research about polymorphs of energetic triazole compounds as well other organic compounds are rarely mentioned in the literature. ${ }^{5}$ In a solid state, the structural transformation was studied using the single-crystal-to-single-crystal (SCSC) and it was explained on the effect of solvent vapors, heat, light and sometimes by applying mechano-chemical forces. ${ }^{6}$

3-Nitro-1,2,4-triazole is a simple and easy to obtain intermediate, which is widely used in the field of medicine and organic semiconductor materials. We have known Form I of 3nitro-1,2,4-triazole, it could be used as an explosive compound although there is no report about its energetic properties. In this paper, we report the two different forms of crystallization, analysis, and phase transformation behaviour of 3-nitro-1,2,4triazole, as well as their energetic properties as insensitive explosives.

\section{Results and discussion}

\section{Polymorphs screening}

The crystallization of 3-nitro-1,2,4-triazole, depending on the conditions employed and solvents used (see the ESI, Tables S1 
and $\mathrm{S} 2 \uparrow$ ), leads to the formation of two different polymorphs. Form I (Fig. 1a) was reported in $1984 .^{7}$ It has been recently demonstrated that the Form II has significant potential in energetic materials. ${ }^{8}$ Extensive experimental crystal polymorph screens were performed to identify the relevant polymorphs of 3-nitro-1,2,4-triazole. In numerous solvent-based crystallization trials only one crystal, Form II, was observed once at ambient pressure, and others are Form I (ESI, Tables S1 and S2 $\dagger$ ). However, both the Forms I and II were stable at ambient temperature and the Form I is more stable at high temperature up to $200{ }^{\circ} \mathrm{C}$, where the Form II is unstable. Interestingly, the Form II undergoes irreversible phase transition to Form I at about $98{ }^{\circ} \mathrm{C}$ (ESI, Table S2 $\dagger$ ). The differential scanning calorimetric (DSC) and powder X-ray diffraction (PXRD) experiment results were clearly indicating this transformation. The crystal structures of Forms I and II are almost identical, except for Form I more disordering than Form II and also, the crystal packing as well as the bond interactions are quite different (ESI, Table S3†).

\section{Crystal and molecular structure description of polymorphs}

The single-crystal X-ray diffraction revealed that Form I crystallized in $P 4_{1} 2_{1} 2$ space group with a calculated density of $1.720 \mathrm{~g} \mathrm{~cm}^{-3}$ based on the diffraction data. In Form I, all of the atoms located in one plane, and each 3-nitro-1,2,4-triazole

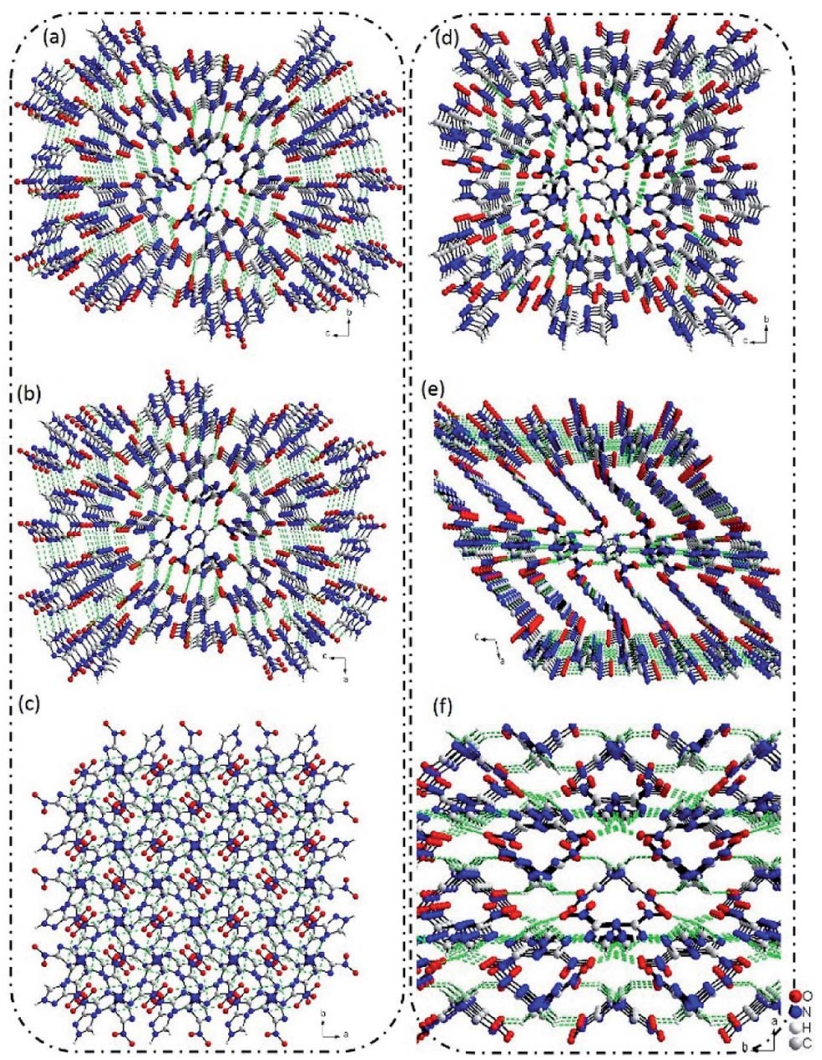

Fig. 1 (a)-(c) The 3D supramolecular structure of Form I view along the $a, b, c$-axis, respectively; (d)-(f) the 3D supramolecular structure of Form II view along the $a, b, c$-axis, respectively. molecule connected with four adjacent molecules via hydrogen bonds of $\mathrm{C}-\mathrm{H} \cdots \mathrm{O}$ and $\mathrm{N}-\mathrm{H} \cdots \mathrm{O}$. The distance of $\mathrm{C} \cdots \mathrm{O}$ and $\mathrm{N} \cdots \mathrm{O}$ are in the range of 3.1501-3.3945 $\AA$ and 3.2385$3.8411 \AA$ A. Through this connected mode, a 3D supramolecular structure was formed (Fig. 1a-c).

Interestingly, when we re-crystal 3-nitro-1,2,4-triazole from methanol and ethyl acetate, a new crystal named Form II was obtained. Form II crystallized in $P 2_{1} / c$ space group with a density of $1.797 \mathrm{~g} \mathrm{~cm}^{-3}$. In Form II, each 3-nitro-1,2,4-triazole molecule interacted with four nearby molecules through hydrogen bonds and $\pi-\pi$ stacking interactions to form a layer structure. The hydrogen bond length is in the range of 105.560118.364. Then the layers stacked in an "AAAA" mode to build a 3D supramolecular structure (Fig. 1e and f). As shown in Fig. 1, the stacking mode of 3-nitro-1,2,4-triazole molecules contained in two crystal Forms are much different. In Form II, regular layer structures were observed along the $b$-axis. However, in Form 1, no layers could be observed along any direction. The supramolecular structure of Form II is similar to the high-energy-density material of 5-nitro- $1 H$-tetrazole. This may explain the higher density of Form II than that of Form I in partly.

To gain more insights towards the different densities, calculated packing coefficient of two crystals, Hirshfeld surface and relative two-dimensional finger print spectra of two Form crystals were analyzed systematically. The calculated packing coefficients of both crystals are $71.9 \%$ and $75.3 \%$, respectively. Generally, high packing coefficient ratio also imply high
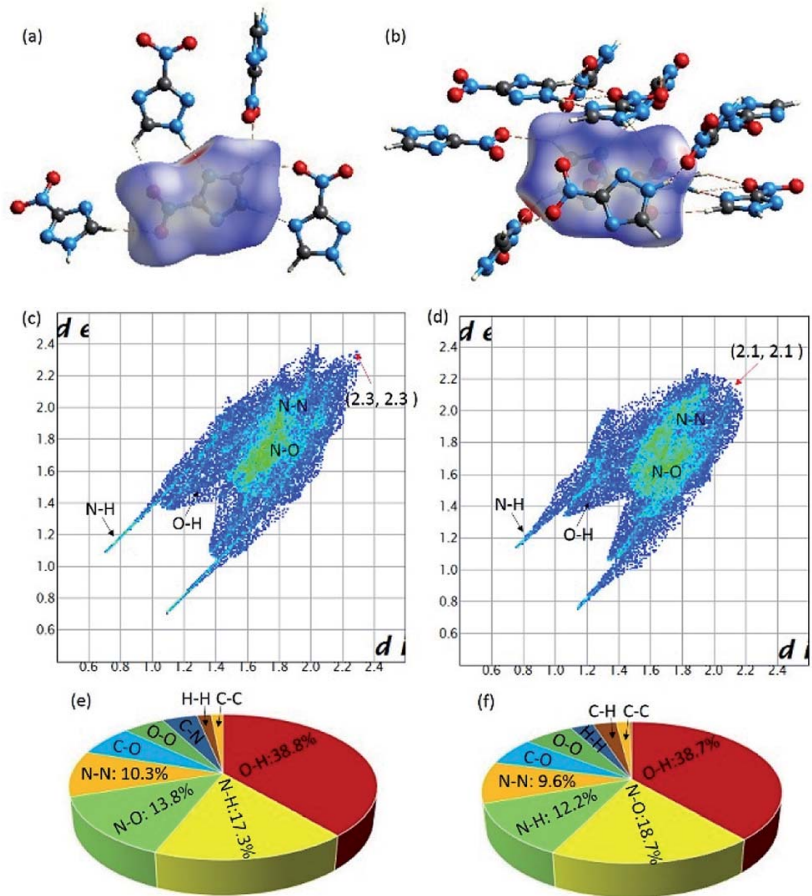

Fig. 2 Hirshfeld surface calculations of Form I (a) and Form II (b); finger print plots of Form I (c) and Form II (d); the individual atomic contact percentage contribution to the Hirshfeld surface of Form I (e) and Form II (f). 
density. In this work, two Form of crystals are constructed by the same molecule. Therefore, the higher packing coefficient demonstrated the higher density. Hirshfeld surface of the molecules contained in different crystal Forms were carried out by Crystalexplorer17.5 software. From the picture of Hirshfeld surface, the red and blue spots demonstrate the high and low contact populations, respectively. As shown in Fig. 2, each 3nitro-1,2,4-triazole molecule interacted with adjacent molecules through strong hydrogen (red spots) and $\pi-\pi$ stacking interaction (white plane). The ratio of hydrogen bond interactions contained in Form I and Form II are 56.1\% and 50.9\%, respectively. From the figure print spots of the Forms, it is shown that the longest distance between two interaction molecules contained in Form I and Form II were appearance at the spots of $(2.3,2.3)$ and $(2.1,2.1)$, respectively, demonstrated the closer interaction were existence in Form II.

Furthermore, it is to be note that intensive O-N interactions were observed from the finger print spots of Form II, which is reflected the existence of strong $\pi-\pi$ stacking interaction, as shown in Fig. 2. The ratio of $\mathrm{O}-\mathrm{N}$ interactions from Form II and Form I are $18.7 \%$ and $13.8 \%$, respectively, demonstrating the existence of higher percentage of interlayer contact in Form II than that contained in Form I. The higher calculated packing coefficient, more hydrogen bonds, and stronger $\pi-\pi$ stacking interaction in Form II may the main reasons, which promote the higher density.

\section{Investigation of stability and transformation behavior of the forms}

Differential scanning calorimetry (DSC) and in situ variabletemperature powder X-ray diffraction (PXRD). Moreover, only a few single crystals of Form II could be obtained from the method discussed above, leading to a question regarding the large-scale preparation of this polymorph, as a pure phase.

To know the nature of phase transition, DSC measurement was carried out from room temperature to $300{ }^{\circ} \mathrm{C}$. It is evident from Fig. 3 that no changes were observed in the energy profile for Form I, except for a sharp exothermic peak at $217^{\circ} \mathrm{C}$, which is due to the decomposition of Form I. However, for Form II (Fig. 3), two exothermic peaks were observed (98 and $217^{\circ} \mathrm{C}$ ). Since the latter peak corresponds to the decomposition point of Form I, it suggests that a phase transition of Form II $\rightarrow$ Form I might have occurred at $98{ }^{\circ} \mathrm{C}$, and it subsequently melted at $217^{\circ} \mathrm{C}$.

Furthermore, the evidence for the phase transition from Form II into Form I was also obtained in situ variabletemperature powder diffraction experiments. It is evident from Fig. 4a that Form I did not show any phase transitions as the position and intensity of the peaks remain intact throughout the process, irrespective of the temperature variations. However, phase transitions of Forms II to Form I are evident from the appearance of new peaks during heating. The transformations are shown in blue and purple in Fig. 4. The patterns in blue and purple are identical to the patterns shown in Fig. 4a for Form I. This unequivocally confirms the transition of Forms II into I before the decomposition of the Forms

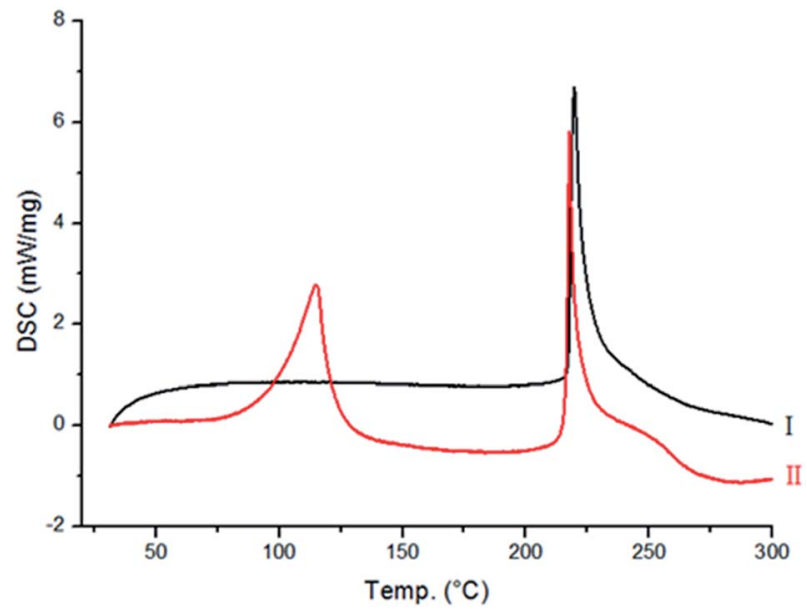

Fig. 3 DSC traces of Forms I-II, heating up to decomposition point.

II. In Form II, the transition is observed between 98 and $115^{\circ} \mathrm{C}$ (with the appearance of the new peaks at $2 \theta 20$, and $23^{\circ}$ and disappearance of peaks at $2 \theta 9,24,27$, and $35^{\circ}$ ) (Fig. 4b).

\section{Phase to phase transformation}

Phase to phase transformation, occurring due to cooperative movement of atoms in the solid state, is an interesting and challenging phenomenon in terms of obtaining good-quality single crystals even after phase transformations, which gives
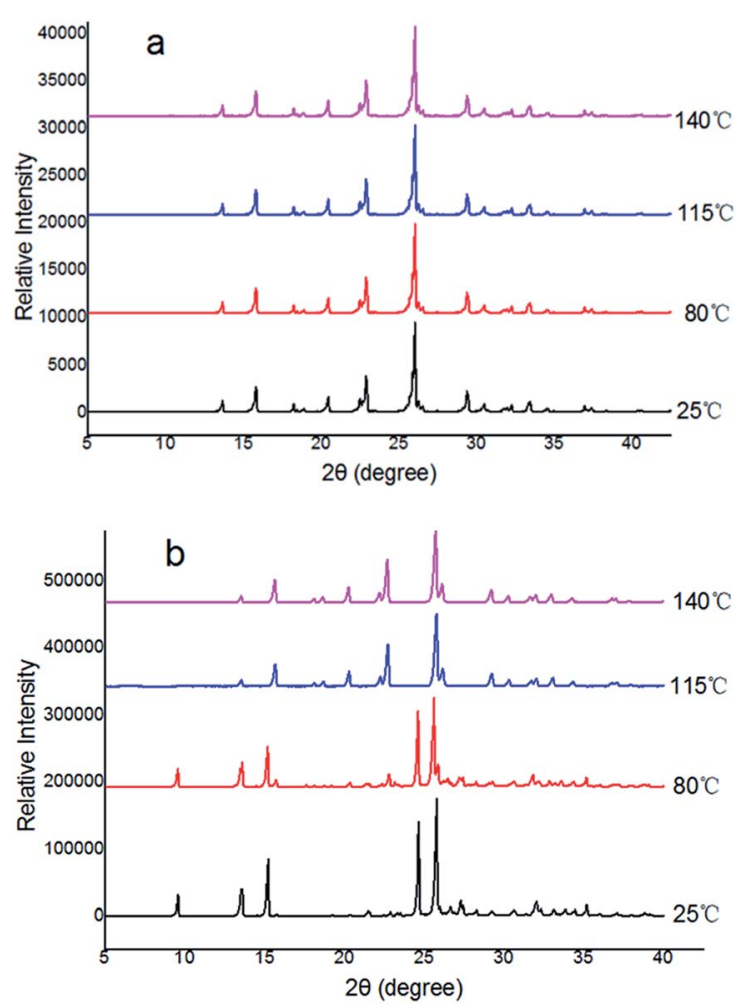

Fig. 4 In situ variable-temperature powder $\mathrm{X}$-ray diffraction patterns for the polymorphs: (a) Form I, (b) conversion of Form II $\rightarrow$ Form I. 
more insight about the mechanism of transformation from one solid form to another. ${ }^{9}$ Single crystals of Form I did not show any changes in the unit cell dimensions during in situ heating even up to $140{ }^{\circ} \mathrm{C}$, demonstrating the stability of Form I, and no unit cell parameters could be obtained above this temperature. However, single crystals of Form II showed a change in the unit cell parameters, and the phase transition occurred at $98{ }^{\circ} \mathrm{C}$, which corresponds to Form II to I transformation. As per our knowledge, the temperature may play a major role to result the phase transition. ${ }^{\mathbf{1 0}}$ Also, it may fact that the two solid forms are isostructural in terms of the arrangement of molecules in both two and three dimensions, making easier movement of atoms in the solid-state.

\section{Physicochemical properties: heat of formation, detonation parameters, and sensitivities}

Density is one of the significant physical characteristics of energetic materials. ${ }^{11}$ The densities of Form I and II are 1.72 and $1.79 \mathrm{~g} \mathrm{~cm}^{-3}$, respectively, which are higher that of TNT. Compared to the Form I, the density of the Form II increases by $0.07 \mathrm{~g} \mathrm{~cm}^{-3}$, which may contribute to the relatively regular molecular arrangement of Form II in the supramolecular structure.

The calculated heats of formation of Form I and II was $146.57 \mathrm{~kJ} \mathrm{~mol}^{-1}$, which were higher than those of both TNT and TATB. Based on calculated heats of formation and experimental, the detonation performances of Form I and Form II, were calculated with EXPLO5 (version 5.05) ${ }^{\mathbf{1 2}}$ in Table 2. Both Form I and II exhibited better detonation performance than TNT and TATB, as expected, the Form II exhibits the highest value $\left(V_{\mathrm{det}}=8213 \mathrm{~m} \mathrm{~s}^{-1}, P_{\mathrm{C}-\mathrm{J}}=27.45 \mathrm{GPa}\right)$, compared to Form I, the detonation velocity increases by $266 \mathrm{~m} \mathrm{~s}^{-1}$, highlight the importance of improving detonation properties of energetic compounds through polymorphs screening. To further evaluate their safer properties, the sensitivities of Form I and II toward impact, friction and electrostatic discharge were tested by using standard procedures (Table 2). Both of them exhibited insensitivities to an electrostatic discharge of approximately $29.24 \mathrm{~J}$. Its impact sensitivities and friction sensitivities were above $40 \mathrm{~J}$ and $360 \mathrm{~N}$ respectively, which are the same as TATB.

Since 3-nitro-1,2,4-triazole-Form II has better detonation performance than TNT and TATB, while retain low sensitivity, it could be used as new insensitive explosive, replacing TNT and TATB.

\section{Experimental}

\section{Chemicals and crystal growth}

3-Nitro-1,2,4-triazole was purchased from Sigma-Aldrich. HPLC grade solvents were used for crystallization. From PXRD, it is confirmed that the commercially available material 3-nitro1,2,4-triazole is found to be Form II. Crystallization was carried out from a wide variety of solvents, solvent mixtures, and other crystallization methods (see the ESI $\dagger$ ), which resulted in two different solid forms labeled as Forms I, II.

\section{Crystallization}

The sample of 3-nitro-1,2,4-triazole ( $\geq 98 \%$ ) used in this work was purchased from Maya Reagent. For crystallization experiments, 3-nitro-1,2,4-triazole was dissolved in a solvent or mixture of solvents and left at ambient temperature (for few days) to allow slow evaporation of solvent until crystals appeared. The solvents used were ethanol (Aldrich, >99.8\%), methanol (Fisher, $>99.5 \%$ ), acetone (Fisher, $>99 \%$ ), acetone (Aldrich, 99.5\% atom\% D), dichloromethane (Fisher, >99\%), and glacial acetic acid (Fisher, >99\%). In addition, the following

Table 1 Crystallographic data for 3-nitro-1,2,4-triazole polymorphs I-II

\begin{tabular}{|c|c|c|}
\hline & Form I (CCDC 1848407) & Form II (CCDC 1848408) \\
\hline Empirical formula & $\mathrm{C}_{2} \mathrm{H}_{2} \mathrm{~N}_{4} \mathrm{O}_{2}$ & $\mathrm{C}_{2} \mathrm{H}_{2} \mathrm{~N}_{4} \mathrm{O}_{2}$ \\
\hline Formula weight & 114.08 & 114.08 \\
\hline Crystal habit & Irregular blocks & Needles \\
\hline Crystal color & Yellow & White \\
\hline Crystal system & Tetragonal & Monoclinic \\
\hline Space group & $P 4_{1} 2_{1} 2$ & $P 2_{1} / c$ \\
\hline$a(\AA)$ & $6.8413(3)$ & $8.7895(6)$ \\
\hline$b(\AA)$ & $6.8413(3)$ & $10.0707(8)$ \\
\hline$c(\AA)$ & $18.8196(12)$ & $9.9645(5)$ \\
\hline$\alpha(\mathrm{deg})$ & 90 & 90 \\
\hline$\beta$ (deg) & 90 & $107.082(6)$ \\
\hline$\gamma(\mathrm{deg})$ & 90 & 90 \\
\hline$V\left(\AA^{3}\right)$ & $880.82(8)$ & $843.10(10)$ \\
\hline$Z$ & 8 & 8 \\
\hline$D_{\text {calc. }}\left(\mathrm{g} \mathrm{cm}^{-3}\right)$ & 1.720 & 1.797 \\
\hline$T(\mathrm{~K})$ & 101.8 & 101.8 \\
\hline$\mu\left(\mathrm{mm}^{-1}\right)$ & 0.152 & 0.159 \\
\hline $2 \theta$ range $(\mathrm{deg})$ & 7.36 to 52 & 6.78 to 52 \\
\hline$F(000)$ & 464 & 464 \\
\hline GOF on $F^{2}$ & 1.098 & 1.078 \\
\hline Final $R$ indexes $\left[I>2 \sigma(I)\right.$ i.e. $\left.F_{\mathrm{o}}>4 \sigma\left(F_{\mathrm{o}}\right)\right]$ & $R_{1}=0.0375, \mathrm{w} R_{2}=0.0860$ & $R_{1}=0.0318, \mathrm{w} R_{2}=0.0734$ \\
\hline Final $R$ indexes [all data] & $R_{1}=0.0410, \mathrm{w} R_{2}=0.0883$ & $R_{1}=0.0378, \mathrm{w} R_{2}=0.0772$ \\
\hline
\end{tabular}


Table 2 Physicochemical properties of Form I and Form II in comparison to TATB and 2,4,6-TNT

\begin{tabular}{|c|c|c|c|c|}
\hline & Form I & Form II & TATB & $2,4,6-\mathrm{TNT}$ \\
\hline Molecular formula & $\mathrm{C}_{2} \mathrm{H}_{2} \mathrm{~N}_{4} \mathrm{O}_{2}$ & $\mathrm{C}_{2} \mathrm{H}_{2} \mathrm{~N}_{4} \mathrm{O}_{2}$ & $\mathrm{C}_{6} \mathrm{H}_{6} \mathrm{~N}_{6} \mathrm{O}_{6}$ & $\mathrm{C}_{7} \mathrm{H}_{5} \mathrm{~N}_{3} \mathrm{O}_{6}$ \\
\hline Molecular mass $\left[\mathrm{g} \mathrm{mol}^{-1}\right]$ & 114.08 & 114.08 & 258.2 & 227.13 \\
\hline Friction sensitivity ${ }^{b}[\mathrm{~N}]$ & 360 & 360 & 360 & 353 \\
\hline ESD test $[\mathrm{J}]$ & 29.24 & 29.24 & 17.75 & - \\
\hline$N^{c}[\%]$ & 49.1 & 49.1 & 33 & 18.50 \\
\hline$\rho^{f}\left[\mathrm{~g} \mathrm{~cm}^{-3}\right]$ & 1.72 & 1.79 & 1.858 & 1.648 (ref. 14) \\
\hline$\Delta H_{\mathrm{f}}^{\circ} g\left[\mathrm{~kJ} \mathrm{~mol}^{-1}\right]$ & 146.57 & 146.57 & 139.8 & -55.5 \\
\hline \multicolumn{5}{|l|}{ EXPLO5 values, V5.05 } \\
\hline$-\Delta_{\mathrm{E}} U^{\circ h}\left[\mathrm{~kJ} \mathrm{~kg}^{-1}\right]$ & 4786 & 4822 & 4520 & 5258 \\
\hline$T_{\mathrm{E}}^{i}[\mathrm{~K}]$ & 3561 & 3530 & - & 3663 \\
\hline$P_{\mathrm{C}-j} j[\mathrm{GPa}]$ & 24.81 & 27.45 & 25.9 & 23.5 \\
\hline
\end{tabular}

mixed solvent systems $(\sim 1: 1$ ratio) were used: methanol/ethyl acetate. Powder XRD studies of the crystallization products were carried out at ambient temperature on a Bruker D8 instrument operating in transmission mode (CuKa1 radiation, Ge monochromated).

Powder XRD analysis of the crystallization products indicated that, with the exception of crystallization from hydroxylamine, all crystallization experiments gave the same product, which we designate as $\alpha$. Crystallization from hydroxylamine, on the other hand, which we designate as $\beta$.

\section{Single-crystal X-ray diffraction}

Details of the single-crystal X-ray diffraction intensity measurements and refinements are given in Table 1. All operations for Forms I, II, I' $\mathrm{I}^{\prime}$, and $\mathrm{II}^{\prime}$ were performed on a BrukerNonius Kappa Apex2 diffractometer, using graphitemonochromated MoK $\alpha$ radiation $(\lambda=0.7107 \AA)$. All diffractometer manipulations, including data collection, integration, scaling, and absorption corrections, for these forms were carried out using the Bruker Apex2 software. ${ }^{15}$ Data collection for Form I and II was carried out at $120 \mathrm{~K}$, using a frame time of $20 \mathrm{~s}$ and a detector distance of $60 \mathrm{~mm}$. The optimized strategy used for data collection consisted of four $\varphi$ and six $\omega$ scan sets, with $0.5^{\circ}$ steps in $\varphi$ or $\omega$. The structures were solved by using SHELXS and refined by least-squares methods using SHELXL. ${ }^{16}$ From the systematic absences, the observed metric constants, and intensity statistics, space groups $P 4_{1} 2_{1} 2$ and $P 2_{1} / c$ were chosen for Forms I, II, respectively, at the beginning; subsequent solution and refinement confirmed the correctness of the choice. The structures (Forms I, II, I', I', and $\mathrm{II}^{\prime}$ ) were solved using SIR92 and subsequent electron-density difference syntheses $^{17}$ and refined (full-matrix least-squares) using the Oxford University Crystals for Windows program. ${ }^{18,19}$ All nonhydrogen atoms were refined using anisotropic displacement parameters.

\section{PXRD}

Powder X-ray diffraction measurements were carried out with a Rigaku Dmax 2500 diffractometer using $\mathrm{Cu} K \alpha$ radiation $(\lambda=$ $1.5418 \AA$ ). The sample holder was a copper block, and a very thin layer of powder sample was pressed on this block. The patterns were collected in the $2 \theta$ range of $5-90^{\circ}$ with a step size of $0.02^{\circ}$ and $1.0 \mathrm{~s}$ counting per step. The copper block with the sample was heated at the rate of $10{ }^{\circ} \mathrm{C} \mathrm{min}^{-1}$. The diffraction pattern was collected while the sample temperature was held constant within $1{ }^{\circ} \mathrm{C}$ of the set temperature, and the data were acquired in $16 \mathrm{~min}$. The diffraction data were collected at room temperature and subsequently after every $10^{\circ} \mathrm{C}$ to monitor the change in structure during heating. The positions of the peaks were fixed by deconvoluting the peaks using Rigaku multipeak separation software available with the diffractometer system.

\section{Thermal analysis}

The DSC experiments were performed using a DSC 1 Star System with STARe Excellence Software from Mettler-Toledo AG. Samples in the range of 3-4 $\mathrm{mg}$ were placed in Al crucibles after surface-drying on filter paper. The sample was heated from 30 to $300{ }^{\circ} \mathrm{C}$ at a rate of $5{ }^{\circ} \mathrm{C} \mathrm{min}^{-1}$.

\section{Conclusions}

To summarize, preparation and rational analysis of two polymorphs of 3-nitro-1,2,4-triazole have been reported and thoroughly characterized. In the two forms, the $-\mathrm{NH}$ group presents that between the $-\mathrm{NO}_{2}$ groups forms intramolecular $\mathrm{N}-\mathrm{H} \cdots \mathrm{O}$ hydrogen bonding. In Forms I and II, molecules interact through $\mathrm{N}-\mathrm{H} \cdots \mathrm{O}$ hydrogen bond formation. In the phase transition of Form II to I has also been demonstrated, Form II is more stable at ambient conditions, whereas Form I is more stable at higher temperatures. Compared to Form I, the density 
of Form II increases by $0.07 \mathrm{~g} \mathrm{~cm}^{-3}$, the detonation velocity increases by $266 \mathrm{~m} \mathrm{~s}^{-1}$, highlight the importance of improving detonation properties of energetic compounds through polymorphs screening. The Form II of 3-nitro-1,2,4-triazole have good detonation properties $\left(V_{\mathrm{det}}=8213 \mathrm{~m} \mathrm{~s}^{-1}, P_{\mathrm{C}-\mathrm{J}}=27.45\right.$ GPa), and low sensitivity (IS $>40 \mathrm{~J}, \mathrm{FS}>360 \mathrm{~N}, \mathrm{ESD}=29 \mathrm{~J}$ ), which make it a competitive candidate for using as new insensitive explosives.

\section{Conflicts of interest}

There are no conflicts to declare.

\section{Acknowledgements}

The authors acknowledge financial support from NSAF (U153062), the National Natural Science Foundation of China (21576026) and the Fundamental Research Funds for the Central Universities.

\section{References}

1 (a) R. Hilfiker, Org. Process Res. Dev., 2007, 11, 649-650; (b) R. J. Davey, Cryst. Growth Des., 2002, 2, 675-676; (c) D. Singhal and W. Curatolo, Adv. Drug Delivery Rev., 2004, 56, 335-347; (d) A. B. Park, L. J. chyall, J. Dunlap, C. Schertz, D. Jonaitis, B. C. Stahly, S. Bates, R. Shipplett and S. Childs, Expert Opin. Drug Discovery, 2007, 2, 145-154.

2 (a) Q. L. Yan, A. Cohen, N. Petrutik, A. Shlomovich, L. Burstein, S. P. Pang and M. Gozin, J. Mater. Chem. A, 2016, 4, 9941-9948; (b) A. Cohen, Y. Z. Yang, Q. L. Yan, A. Shlomovich, N. Petrutik, L. Burstein, S. P Pang and M. Gozin, Chem. Mater., 2016, 28, 6118-6126; (c) W. Liu, Q. H. Lin, Y. Z. Yang, X. J. Zhang, Y. C. Li, Z. H. Lin and S. P. Pang, Chem.-Asian J., 2014, 9, 479-486.

3 I. J. Powell, Propellants, Explos., Pyrotech., 2016, 41, 409-413. 4 (a) W. Liu, S. h. Li, Y. C. Li, Y. Z. Yang, Y. Yu and S. P. Pang, J. Mater. Chem. A, 2014, 2, 15978-15986; (b) C. Qi, S. H. Li, Y. C. Li, Y. Wang, X. X. Zhao and S. P. Pang, Chem.-Eur. J., 2012, 18, 16562-16570.

5 (a) L. Mazur, A. E. Koziol, K. N. Jarzembska, R. Paprocka and B. Modzelewska-Banachiewicz, Cryst. Growth Des., 2017, 17, 2104-2115; (b) J. Z. Huo, X. M. Su, X. X. Wu, Y. Y. Liu and B. Ding, CrystEngComm, 2016, 18, 6640-6652; (c) C.-P. Li, J.-M. Wu and M. Du, Inorg. Chem., 2011, 50, 9284-9289; (d) J. P. Reddy, D. Swain and V. R. Pedireddi, Cryst. Growth Des., 2014, 14, 5064-5071; (e) T. S. Thakur, R. Sathishkumar, A. G. Dikundwar, T. N. Guru Row and G. R. Desiraju, Cryst. Growth Des., 2010, 10, 4246-4249.

6 A. Chaudhary, A. Mohammad and S. M. Mobin, Cryst. Growth Des., 2017, 17, 2893-2910.

7 G. Evrard, F. Durant and A. Michel, Bull. Soc. Chim. Belg., 1984, 93, 233-234.
8 M. Hemamalini and H.-K. Fun, Acta Crystallogr., 2011, E67, 015.

9 (a) E. N. Duesler, K. E. Wiegers, D. Y. Curtin and I. C. Paul, Mol. Cryst. Liq. Cryst., 1980, 59, 289-298; (b) H. Nakanishi, W. Jones and J. M. Thomas, Chem. Phys. Lett., 1980, 71, 4448; (c) V. Enkelmann, G. Wegner, K. Novak and K. B. Wagener, J. Am. Chem. Soc., 1993, 115, 10390-10391; (d) J. L. Atwood, L. J. Barbour, A. Jerga and B. L. Schottel, Science, 2002, 298, 1000-1002; (e) A. Natarajan, C. K. Tsai, S. I. Khan, P. McCarren, K. N. Houk and M. A. GarciaGaribay, J. Am. Chem. Soc., 2007, 129, 9846-9847; (f) J. A. G. D. Ripmeester Enright, C. I. Ratcliffe, K. A. Udachin and I. L. Moudrakovski, Chem. Commun., 2006, 4986-4996; $(g)$ J. Tian, P. K. Thallapally, S. J. Dalgarno and J. L. Atwood, J. Am. Chem. Soc., 2009, 131, 13216-13217; (h) E. Y. Lee and M. P. Suh, Angew. Chem., 2004, 116, 28582861; (i) J. J. Vittal, Coord. Chem. Rev., 2007, 251, 17811795; (j) O. Ohmori, M. Kawano and M. Fujita, J. Am. Chem. Soc., 2004, 126, 16292-16293; (k) E. Deiters, V. Bulach and M. W. Hosseini, Chem. Commun., 2005, 3906-3908; (l) G. J. Halder and C. J. Kepert, Aust. J. Chem., 2006, 59, 597-604; (m) K. L. Gurunatha, S. Mohapatra, P. A.Suchetan and T. K. Maji, Cryst. Growth Des., 2009, 9, 3844-3847; (n) D. Bradshaw, J. E. Warren and M. Rosseinsky, Science, 2007, 315, 977-979; (o) C. Q. li, D. C. Swenson and L. R. MacGillivray, Angew. Chem., Int. Ed., 2005, 44, 3569-3572; (p) S. Supriya and S. K. Das, J. Am. Chem. Soc., 2007, 129, 3464-3465; (q) I. Halasz, Cryst. Growth Des., 2010, 10, 2817-2823.

10 (a) E. Lee, Y. Kim, J. Heo and K.-M. Park, Cryst. Growth Des., 2015, 15, 3556-3560; (b) T. T. Zhang, Y. Lu, Z. M. Zhang, Q. Lan, D. Liu and E. B. Wang, Inorg. Chim. Acta, 2014, 411, 128-133; (c) S. Uchida, E. Takahashi and N. Mizuno, Inorg. Chem., 2013, 52, 9320-9326.

11 X. X. Zhao, S. H. Li, Y. Wang, Y. C. Li, F. Q. Zhao and S. P. Pang, J. Mater. Chem. A, 2016, 4, 5495-5504.

12 M. SućeskaEXPLO5.5 program, Zagreb, Croatia, 2010.

13 R. Mayer, J. Köhler and A. Homburg, Explosives, Wiley-VCH, Weinheim, 5th edn, 2002.

14 N. I. Golovina, A. N. Titkov, A. V. Raevskii and L. O. Atovmyan, J. Solid State Chem., 1994, 113, 229-238.

15 Apex2, Version 2 User Manual, M86-E01078, Bruker Analytical X-ray Systems, Madison, WI, 2006.

16 G. M. Sheldrick, SHELXTL-PLUS Program for Crystal structure Solution and Refinement, University of Gottingen, Gottingen, Germany, 1997.

17 A. Altomare, G. Cascarano, C. Giacovazzo, A. Guagliardi, M. C. Burla, G. Polidori and M. Camalli, J. Appl. Crystallogr., 1994, 27, 435.

18 P. W. Betteridge, J. R. Carruthers, R. I. Cooper, K. Prout and D. J. Watkin, J. Appl. Crystallogr., 2003, 36, 1487.

19 C. K. Prout and L. J. Pearce, CAMERON, Chemical Crystallography Laboratory, Oxford, U.K., 1996. 